Article

\title{
The Antimicrobial Effectiveness and Cytotoxicity of the Antibiotic-Loaded Chitosan: ECM Scaffolds
}

\author{
Shayla Goller ${ }^{1}$ and Neill J. Turner ${ }^{1,2, * \mathbb{D}}$ \\ 1 McGowan Institute for Regenerative Medicine, University of Pittsburgh, Pittsburgh, PA 15219, USA; \\ Shay.Goller@pitt.edu \\ 2 Department of Surgery, University of Pittsburgh, Pittsburgh, PA 15260, USA \\ * Correspondence: turnern@upmc.edu; Tel.: +1-412-624-5272
}

Received: 16 April 2020; Accepted: 14 May 2020; Published: 16 May 2020

\begin{abstract}
Background: The development of multifunctional wound dressings with the ability to control hemostasis, limit infection and promote rapid wound healing and constructive tissue remodeling has been a challenge for many years. In view of these challenges, a hybrid scaffold platform was developed that combined two different extracellular matrices (ECM): ECM from decellularized mammalian tissue and ECM (chitosan) from crustaceans. Both types of ECM have well established clinical benefits that support and promote wound healing and control hemostasis. This scaffold platform could also be augmented with antibiotics to provide bactericidal activity directly to the wound site. Methods: Four different scaffold formulations were developed containing chitosan supplemented with either $20 \%$ or $50 \%$ urinary bladder matrix (UBM) hydrogel or $1 \%(w / v)$ or 10\% (w/v) UBM-ECM particulates. 100\% chitosan scaffolds were used as controls. The scaffolds were augmented with either minocycline or rifampicin. Escherichia Coli and Staphylococcus Aureus were used to assesses antimicrobial efficacy and duration of activity, while neutral red uptake assays were performed to establish direct and indirect cytotoxicity. Results: Results showed that scaffold handling properties, scaffold integrity over time and the efficacy and release rate of loaded antibiotics could be modified by altering scaffold composition. Moreover, antibiotics were easily released from the scaffold and could remain effective for up to $24 \mathrm{~h}$ by modifying the scaffold composition. Variable results with cytotoxicity testing show that further work is required to optimize the scaffold formulations but these proof of principle experiments suggest that these scaffolds have potential as bioactive wound dressings.
\end{abstract}

Keywords: chitosan; extracellular matrix; antimicrobial; biocompatible; scaffold; wound healing; regenerative medicine

\section{Introduction}

At its simplest, a superficial wound can be described as damage to the skin due to burn, trauma or incision. However, this description fails to appreciate the complex nature of the wound environment and the unique problems that define the severity of the wound as it relates to variables such as trauma type, location and size. Severe wounds can lead to death as a result of infection or blood loss and frequently require specialist wound dressings and intensive care. However, while there is a high demand for wound dressings to enhance hemostasis, accelerate tissue repair and combat infection, advances in wound dressing technology are lacking due in part to the intrinsic complexity of the wound healing process. Ideal wound dressings should conform to the wound, help maintain a moist environment while assisting with the removal of wound exudates and facilitate the wound healing process. Additionally, attributes such as control of infection, hemostasis and promotion of constructive tissue remodeling would be desirable features. Choice of wound dressing ranges 
from the relatively simple, such as paraffin-gauze, to complex hydrogels and colloids that may or may not contain bioactive factors to promote angiogenesis or re-epithelialization. More recently, the development of biologic dressings for wound repair has resulted in dressing materials that attempt to restore the wound microenvironment by providing either bioactive factors, extracellular matrix (ECM) components or both to stimulate granulation tissue formation, angiogenesis and re-epithelialization. Two such materials are chitosan and ECM derived from decellularized tissues.

Chitosan is a $\beta$-1,4-linked polymer of glucosamine (2-amino-2-deoxy- $\beta$-D-glucose) and lesser amounts of $\mathrm{N}$-acetylglucosamine. It is a derivative of chitin (poly-N-acetylglucosamine), which is the second most abundant biopolymer after cellulose [1]. The structural characteristics of chitosan mimic glycosaminoglycan components of the extracellular matrix, while the biocompatibility, biodegradability, antibacterial [2,3], antioxidant activities and mucoadhesive properties impart versatility. Various kinds of modification of chitosan have been investigated in recent years using acylation, alkylation, carboxymethylation and quaternization [4]. Recently, the antibacterial and antifungal activities of chitosan have been followed with great interest [2,5-7]. Furthermore, incorporation of antibacterial agents into the chitosan backbone offers excellent antibacterial properties $[3,8,9]$. Chitosan also has a strong affinity for binding with red blood cells and blood components allowing chitosan materials to rapidly clot blood [10-12]. Chitosan-derived materials have recently gained regulatory approval in the USA for use in bandages and other hemostatic materials [13,14]. In addition, chitosan is known to modulate the functions of inflammatory cells to promote granulation tissue formation [15-17].

ECM scaffolds derived from decellularized tissues represent the secreted products of resident cells within each tissue and organ and include structural components such as collagen, laminin and hyaluronan as well as secreted growth factors, nanovesicles and other signaling molecules. These molecular components are arranged in tissue specific patterns which are determined by the physiologic and biomechanical requirements of each tissue [18]. The biologic properties of the matrix are only partially understood, but they are known to affect the interaction with resident cells and infiltrating cells. ECM scaffolds modulate cell behavior including alteration of macrophage phenotype, proliferation, mobilization, and differentiation of stem and progenitor cells, and regulation of angiogenesis, among others [19-22]. Moreover, the degradation of these scaffolds releases embedded nanovesicles and cryptic peptide molecules, which play a key role in the biological activity of these materials $[23,24]$ including antimicrobial activity.

While both chitosan and ECM scaffolds possess antimicrobial activity, the exact mechanisms of the antimicrobial actions are still uncertain. Therefore, to maximize the antimicrobial effects combination of these scaffold materials with an antibiotic would be desirable. For example, it has been proposed that interaction between acidic, or positively charged chitosan molecules and negatively charged microbial cell membranes leads to the disruption of microbial membrane, and subsequently the leakage of the intracellular components [25-27].

The overall goal of this project was to develop a hybrid wound dressing composed of chitosan and ECM proteins along with an antibiotic that would be an effective hemostatic and antimicrobial dressing. For the present study the objectives were to perform in vitro testing of (1) the effectiveness and duration of antimicrobial activity; (2) the direct and indirect cytotoxicity of the antibiotic containing scaffolds in order to identify formulations for future in vivo testing.

\section{Materials and Methods}

\subsection{Preparation of Chitosan:ECM Scaffolds}

Chitosan solutions were prepared by dissolving $2 \%(w / v)$ chitosan powder ( $85 \%$ deacetylated, Sigma Aldrich, St. Louis, MO, USA) in dilute acetic acid ( $2 \% v / v)$ under clean conditions. Endotoxin content of the prepared chitosan solution was assessed using the Pierce Limulus Amebocyte Lysate (LAL) Chromogenic Endotoxin Quantitation Kit (ThermoFisher Scientific, Waltham, MA, USA) following the manufacturers recommended protocol. Endotoxin levels were expressed as EU/mL. 
ECM was prepared from porcine urinary bladders (UBM) as previously described [28,29]. Bladders were briefly harvested from market-weight pigs immediately after death. Excess connective and adipose tissues were removed from the serosal surface of the bladder and the apex of the bladder was removed. The bladder was then split longitudinally from the apical opening to the neck of the bladder, forming a rectangular sheet. Mechanical delamination was performed to remove the he tunica serosa, tunica muscularis externa, and tunica submucosa, as well as the majority of the muscularis mucosa. The remaining tissue consisted of only the basement membrane and tunica propria. Decellularization and disinfection was completed by washing with $0.1 \%$ peracetic acid $/ 4 \%$ ethanol solution for $2 \mathrm{~h}$ followed by phosphate-buffered saline solution (PBS) ( $\mathrm{pH}$ 7.4) and water washes. The decellularized tissue was then frozen and lyophilized.

Two forms of ECM were then prepared to be combined with the chitosan solution. First, the lyophilized ECM was comminuted into a powder using a Wiley Mill with a 40-mesh screen. The resulting powder was added to the chitosan solution at either $1 \%$ or $10 \%(w / v)$ to form two scaffold formulations. Second, the comminuted powder was digested with pepsin for form a solubilized ECM hydrogel as previously described [27]. Briefly, the UBM-ECM powder was solubilized by partial enzymatic digestion in a $1 \mathrm{mg} / \mathrm{mL}$ pepsin (Sigma-Aldrich) solution in $0.01 \mathrm{~N} \mathrm{HCl}$ for $48 \mathrm{~h}$ at a concentration of $10 \mathrm{mg} \mathrm{ECM} / \mathrm{mL}$ solution (dry wt/vol). To prepare chitosan:ECM scaffolds, the solubilized ECM was brought to physiologic $\mathrm{pH}$ by adding $1 / 10$ the volume of $0.1 \mathrm{~N} \mathrm{NaOH}$, the solution was combined with the chitosan solution at either 80:20 or 50:50 ratios of chitosan to ECM. The resulting slurries of either chitosan and ECM powder or chitosan:ECM gel were poured into $60 \mathrm{~mm}$ petri dishes (approx. $5 \mathrm{~mL}$ per dish) and then frozen and lyophilized forming a sponge like scaffold. Scaffolds consisting of $100 \%$ chitosan a were also prepared in a similar way for comparison control. Scaffolds consisting of $100 \%$ ECM hydrogel were not used as the lyophilized material proved too friable to make a handleable dressing and would rapidly dissolve when placed in a wet environment.

\subsection{Antibiotic Loading of Scaffolds}

Chitosan ECM scaffolds were augmented with one of two different antibiotics, rifampicin and minocycline. These antibiotics were chosen as they are already approved for use in topical dressings. Since commercially available antibiotic sensitivity testing discs were used for positive controls $(30 \mu \mathrm{g} / 6$ $\mathrm{mm}$ diameter disc for minocycline and $5 \mu \mathrm{g} / 6 \mathrm{~mm}$ diameter disc for rifampicin, (BD BBL Sensi-disc, Becton Dickinson, Franklin Lakes, NJ, USA)) the antibiotic concentration loaded into the chitosan:ECM scaffolds was matched and scaled to the $60 \mathrm{~mm}$ petri dishes ( $3 \mathrm{mg}$ per dish for minocycline and $0.5 \mathrm{mg}$ per dish for rifampicin). The antibiotic powder was added to the chitosan:ECM slurry and stirred until the antibiotic had completely dissolved. The material was then frozen and lyophilized as for the nonantibiotic containing scaffolds.

\subsection{Direct Antimicrobial Assay}

A modification of the Kirby-Bauer antibiotic sensitivity test [30] was used to test the antimicrobial effectiveness of the different chitosan:ECM scaffold formulations when placed in direct contact with bacterial. Briefly, clinical isolates of Staphylococcus Aureus (ATCC 29213) and Escherichia Coli (ATCC 25922) were cultured and growth curves of absorbance vs colony forming units (CFU)/mL for both strains were established. For each bacterial strain, tryptic soy agar plates $(100 \mathrm{~mm})$ were prepared and $100 \mu \mathrm{L}$ of bacterial suspension $\left(1.5 \times 10^{8} \mathrm{CFU} / \mathrm{mL}\right)$ was spread across the plate to form a lawn culture.

Using a sterile biopsy punch, $6 \mathrm{~mm}$ discs of the chitosan:ECM scaffolds were prepared and placed onto the inoculated agar plates with sterile forceps. The discs were placed on the plate using a template to ensure $24 \mathrm{~mm}$ center to center spacing between each disc. As a comparison control, antibiotic sensitivity testing discs for rifampicin and minocycline (BD BBL Sensi-disc) were used. The plates were then cultured overnight at $37^{\circ} \mathrm{C}$ and the zone of inhibition around the individual discs was measured using calipers. Each combination of scaffold was tested in triplicate and the average zone of inhibition calculated and expressed as a percentage of the control disc. 


\subsection{Measurement of Antimicrobial Activity Duration}

To test the duration of the antimicrobial activity of the chitosan:ECM scaffolds with and without antibiotics, $6 \mathrm{~mm}$ discs of each scaffold were incubated for up to $24 \mathrm{~h}$ in $500 \mu \mathrm{L}$ of tryptic soy broth, with the supernatant being collected at 1, 2, 3, 4, 8 and $24 \mathrm{~h}$. At each timepoint the entire $500 \mu \mathrm{L}$ volume was collected and replaced with fresh tryptic soy broth. Thus, each time point represents the release of antimicrobial components between these time points and not the accumulated concentration over time allowing the duration of antimicrobial effectiveness to be measured. Two assays were used to measure the antimicrobial duration a growth kinetic assay and an agar well diffusion assay.

To perform the growth kinetic assay, log phase aliquots of either Staph. Aureus (ATCC 29213) and E. Coli (ATCC 25922) were prepared at a density of $3 \times 10^{8} \mathrm{CFU} / \mathrm{mL}$ and $100 \mu \mathrm{L}$ was added to the well of a 96-well plate. To each bacterial culture, $100 \mu \mathrm{L}$ of chitosan:ECM scaffold supernatant was added and mixed thoroughly. The plate was then incubated at $37^{\circ} \mathrm{C}$ for $18 \mathrm{~h}$ with absorbance at $600 \mathrm{~nm}$ measured every $20 \mathrm{~min}$ using a Spectramax M2 plate reader (Molecular Devices, San Jose, CA, USA). Bacterial aliquots supplemented with $100 \mu \mathrm{L}$ tryptic soy broth were used as positive controls for bacterial growth while tryptic soy broth alone was used as a negative control. All assays were completed in triplicate. The natural log of the absorbance was calculated and used to plot growth curves for each experimental group. The slope of the curve over the exponential growth phase was calculated by linear regression. Where no exponential growth was seen the slope was calculated over the entire 18 time period and slopes that were not significantly different from zero were assumed to show no growth while slopes that were significantly different were assumed to show bacterial growth that did not reach the exponential phase. The lag time was calculated by extrapolating the growth rate line back to the initial ln OD value at time zero.

The agar well diffusion assay was performed in a similar way to the Kirby-Bauer antibiotic sensitivity test. In this case, tryptic soy agar plates $(100 \mathrm{~mm})$ were prepared by as before with tryptic soy $100 \mu \mathrm{L}$ of bacterial suspension $\left(1.5 \times 10^{8} \mathrm{CFU} / \mathrm{mL}\right)$ spread across the plate to form a lawn culture. Using a sterile $6 \mathrm{~mm}$ biopsy punch a core of agar was removed from the plate creating a well. The wells were placed on the plate using a template to ensure $24 \mathrm{~mm}$ center to center spacing between each well. To each well $100 \mu \mathrm{L}$ of chitosan:ECM scaffold supernatant was added, and the plates were then cultured overnight at $37^{\circ} \mathrm{C}$. Soluble antimicrobial agents diffused into the agar from the well creating a zone of inhibition which was then measured using calipers. Each combination of scaffold was tested in triplicate and the average zone of inhibition calculated.

\subsection{Measurement of Direct Cytotoxicity}

The direct cytotoxicity of the antibiotic-loaded chitosan:ECM scaffolds was tested following the ISO10993 standard for in vitro cytotoxicity. Human microvascular endothelial cells (HMEC-1, provided by Dr Francisco Candal, Centers for Disease Control) were used as an established cell line for the assay which were cultured in standard medium 199 supplemented with $10 \%$ fetal bovine serum, 10,000 U penicillin and 10,000 $\mu \mathrm{g} / \mathrm{mL}$ streptomycin (Lonza Biologics, Basel, Switzerland). Scaffold samples for the assay were prepared by taking a $10 \mathrm{~mm}$ diameter sample with a biopsy punch. The samples were then sterilized by ethylene oxide.

To perform the cytotoxicity assay, HMEC- 1 cells were seeded into $35 \mathrm{~mm}$ tissue culture dishes at a density of $1.5 \times 10^{5}$ cells $/ \mathrm{mL}$ with $1 \mathrm{~mL}$ of media per well. The cells were incubated for $24 \mathrm{~h}$ to form a semiconfluent monolayer (60-70\% confluence). After $24 \mathrm{~h}$, the culture medium was removed, and a sterile $10 \mathrm{~mm}$ diameter sample of each scaffold was placed in the center of the dish directly over the cell monolayer. Fresh media was added to the dishes, while ensuring the scaffold remained in contact with the cells and the cells were incubated for a further $24 \mathrm{~h}$. Untreated cells were included as a positive control and a certified cytotoxic scaffold control (polyetherurethane (PU) film containing zinc diethyldithiocarbamate (ZDEC). Japanese Food and Drug Safety Center, Kanagawa, Japan) was used as a negative control. 
The measurement of neutral red dye uptake was used as a quantitative indication of cell number and viability based on the work by Borenfreund and Puerner [31]. The scaffold materials were removed from the dishes and the culture medium was aspirated. The dishes were washed twice with phosphate buffered saline (PBS) and $1 \mathrm{~mL}$ of neutral red medium ( $1 \mathrm{~mL}$ of neutral red stock $(0.4 \mathrm{~g}$ neutral red in $100 \mathrm{~mL}$ type I water) in $79 \mathrm{~mL}$ medium 199) was added and the dishes incubated for $3 \mathrm{~h}$. Following incubation, the dye solution was removed, and the dishes washed twice with PBS. After aspirating the PBS solution, $1.5 \mathrm{~mL}$ of neutral red eluent (1\% glacial acetic acid in $50 \%$ ethanol) was added and the dishes were placed on a shaker for $10 \mathrm{~min}$ at $100 \mathrm{rpm}$ until the neutral red had been extracted from the cells and formed a homogenous solution. The solution was then collected and the absorbance @540 nm measured.

\subsection{Measurement of Indirect Cytotoxicity}

Measurement of indirect cytotoxicity used the same neutral red uptake assay but was performed in 96 well plates with culture medium extracts from the different scaffold materials. To prepare the scaffold extracts, $6 \mathrm{~mm}$ discs of each scaffold were incubated for up to $24 \mathrm{~h}$ in $500 \mu \mathrm{L}$ of HMEC- 1 culture medium with the supernatant being collected at 1, 2, 3, 4, 8 and $24 \mathrm{~h}$. HMEC-1 cells were resuspended at a concentration of $1.5 \times 10^{5}$ cells $/ \mathrm{mL}$ and $100 \mu \mathrm{L}$ of cell suspension added to the wells of a 96-well plate and incubated for $24 \mathrm{~h}$ at $37^{\circ} \mathrm{C}$. After incubation, the culture medium was removed and $100 \mu \mathrm{L}$ of each scaffold extract was added to the wells. Untreated cells were included as positive controls. The plates were then incubated for a further $24 \mathrm{~h}$ before the neutral red uptake assay was performed. The neutral red uptake assay was performed using the same methods as for the direct cytotoxicity assay but with the volumes reduced to $100 \mu \mathrm{L}$ for the 96-well plate. Again, absorbance of the neutral red dye was measured @540 nm.

\subsection{Statistical Analysis}

All experiments were performed in triplicate and the average values were used for statistical analysis using analysis of variance (ANOVA), the null hypothesis being that there was no difference between scaffolds for each test being performed. $p \leq 0.05$ was used to identify significant differences.

\section{Results}

\subsection{Scaffold Properties}

Representative images of the prepared scaffolds are shown in Figure 1. Endotoxin testing showed that the prepared chitosan solution contained 5.03 EU/mL. The prepared scaffolds therefore contained endotoxin proportional to the amount of chitosan used in their fabrication. All the scaffold formulations that consisted of 100\% chitosan or 80:20 and 50:50 chitosan:ECM hydrogel formed a fibrous sponge like scaffold following lyophilization. The $100 \%$ chitosan scaffolds had a firm and dense, but flexible, structure that was easily cut with a biopsy punch to obtain test samples. The scaffolds incorporating ECM hydrogel had a softer consistency than $100 \%$ chitosan, with the softness increasing with increasing ECM hydrogel percentage. Obtaining biopsy punch samples for testing was still possible. The scaffolds that incorporated particulate ECM had a firmer, less flexible structure than those made with ECM hydrogel or chitosan alone. The 10\% ECM scaffolds had a solid inflexible structure that was very easy to cut and showed very little compression. Addition of the rifampicin and minocycline antibiotics colored the scaffold either orange or yellow respectively showing that the antibiotic was distributed homogenously throughout the scaffolds. 


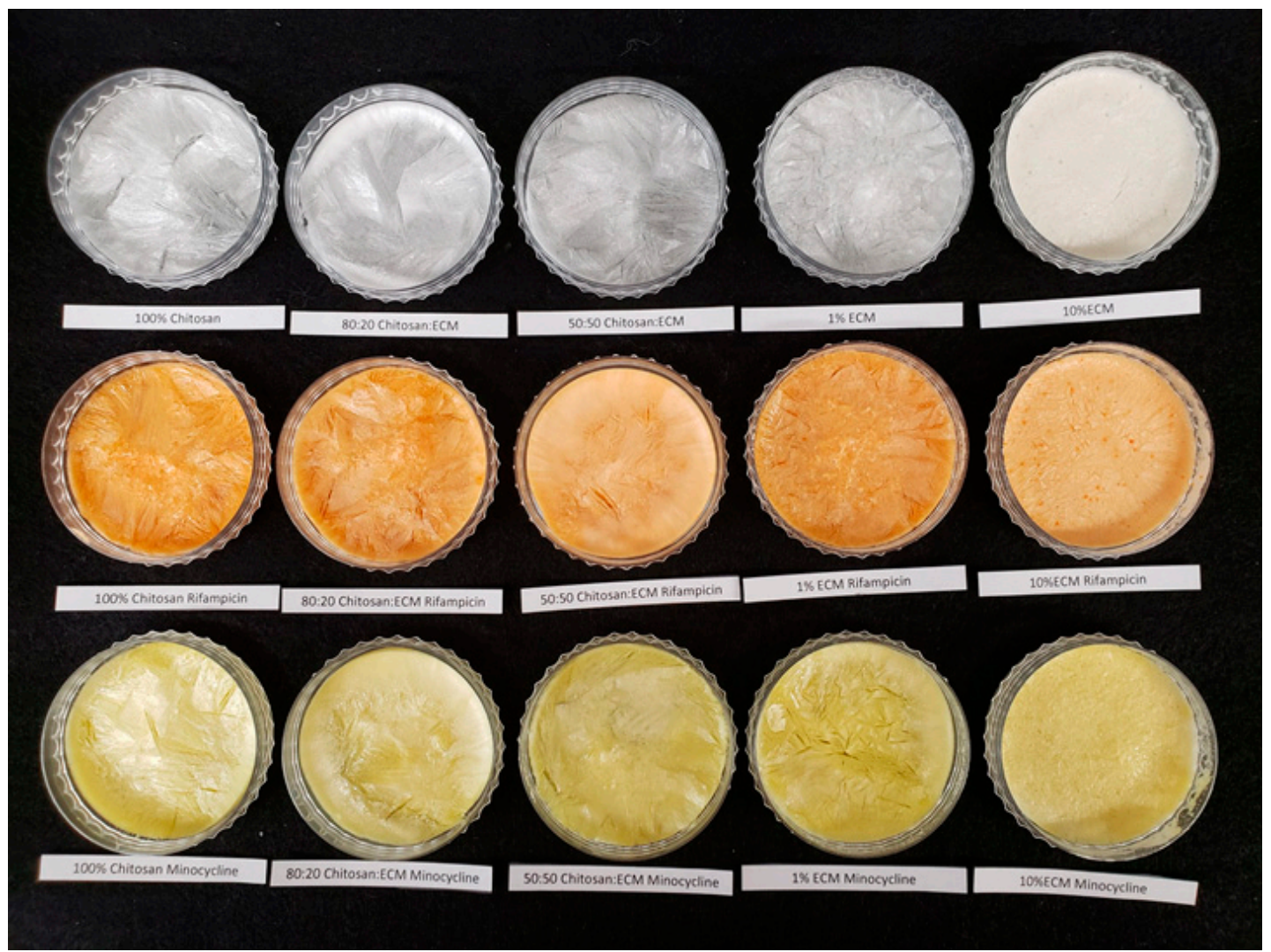

Figure 1. Representative images of the prepared scaffold materials with and without rifampicin and minocycline antibiotic. Scaffolds were formulated as 100\% chitosan, 80/20 and 50/50 chitosan:extracellular matrices (ECM) hydrogel and 1\% (w/v) and 10\% (w/v) ECM powder in chitosan.

When hydrated, notable differences between the scaffolds were observed. The $100 \%$ chitosan scaffolds retained their structure when hydrated and showed no signs of degradation of dissolution of the fibrous structure over time. The 80:20 chitosan:ECM scaffolds softened when hydrated becoming slightly adhesive to any surface upon which they were placed and over time formed a semitranslucent gel. The 50:50 chitosan:ECM scaffolds quickly formed a translucent gel (approximately 5-10 min) when hydrated and were more adhesive to a surface that the $100 \%$ or $80: 20$ scaffolds. Over time, the 50:50 chitosan:ECM scaffolds lost their fibrous structure and after $24 \mathrm{~h}$ had turned completely to hydrogel that could not be picked up with forceps. The 1\% ECM and 10\% ECM scaffolds both retained their structure following hydration but swelled in volume over a $24 \mathrm{~h}$ period. While the $1 \%$ scaffolds retained their shape after $24 \mathrm{~h}$, the $10 \%$ ECM scaffolds began to crumble with increasing hydration time eventually forming a paste-like putty after $24 \mathrm{~h}$ that could still be handled by forceps but could be spread like a cream when lateral forces were applied. Scaffolds made from $100 \%$ ECM hydrogel were also made, while these scaffolds could be cut with a biopsy punch to obtain test samples, they had a very soft, friable structure that was easily disrupted and when hydrated these scaffolds rapidly reverted to hydrogel. These handling characteristics made them unsuitable for testing and they were excluded from the subsequent experiments.

\subsection{Direct Antimicrobial Effects}

The chitosan:ECM scaffold formulations showed differences in bacterial response to the antibiotics used in the study as well as differences in the effectiveness of the antibiotic due to scaffold composition. Figure 2 shows the zones of inhibition in response to the control discs ( 5 ug for rifampicin (Figure 2A,C) and $30 \mathrm{ug}$ for minocycline (Figure 2B,D) for Staph. Aureus and E. Coli, respectively. The clinical isolate of Staph. Aureus used in the study was found to contain some rifampicin resistant bacteria as shown by 
the small bacterial colonies growing within the zone of inhibition (Figure 2A) but showed no resistance to the minocycline antibiotic (Figure 2B). The clinical isolate of E. Coli showed some resistance to the rifampicin antibiotic demonstrated by the reduced size of the zone of inhibition (Figure 2C) but showed no resistance to the minocycline (Figure 2D). These zones of inhibition were measured and used to establish a baseline resistance for the two bacterial strains to compare the chitosan:ECM scaffold combinations.

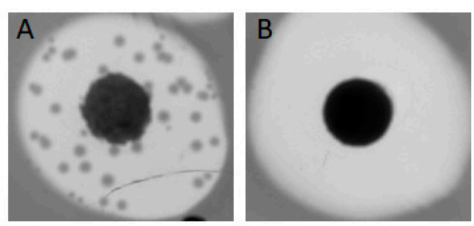

Staph. Aureus Zones of Inhibition

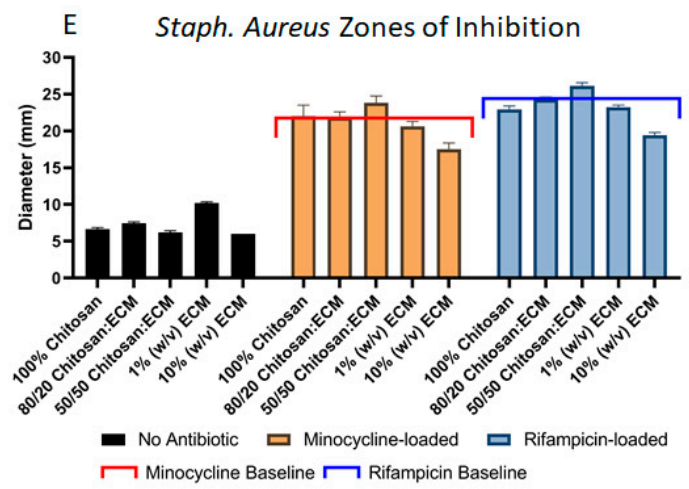

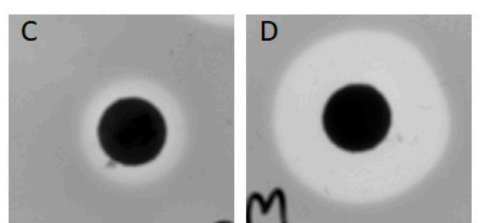

E. Coli Zones of Inhibition

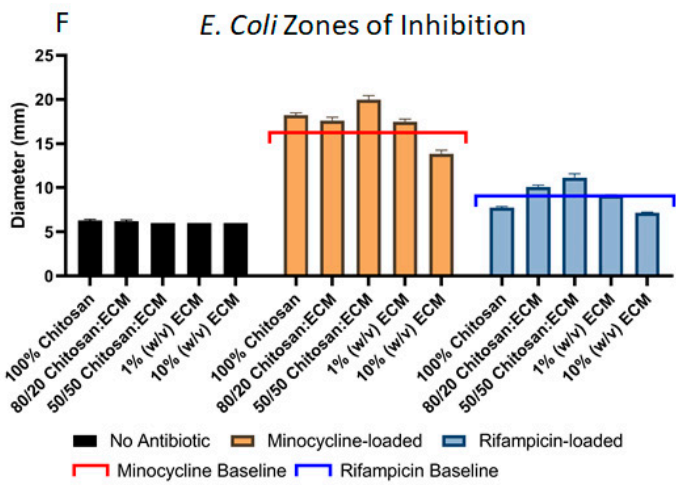

Figure 2. Direct antimicrobial effects of different chitosan:ECM scaffold formulations. (A) zone of inhibition of Staphylococcus Aureus bacteria exposed to rifampicin test disc showing presence of rifampicin resistant colonies; (B) zone of inhibition of Staph. Aureus bacteria exposed to minocycline test discs; (C) zone of inhibition of Escherichia Coli bacteria exposed to rifampicin control disc showing resistance to this antibiotic; (D) zone of inhibition of E. Coli exposed to minocycline test disc; (E) graph showing the measured zones of inhibition when Staph. Aureus were exposed to the different scaffold formulations (red and blue lines show size of the zone of inhibition to the control discs for comparison); (F) graph showing the measured zones of inhibition when E. Coli were exposed to the different scaffold formulations (red and blue lines show size of the zone of inhibition to the control discs for comparison).

\subsubsection{Direct Antimicrobial Effects on Staph. Aureus Bacteria}

Notable differences between the scaffolds could be seen (Figure 2E). While in general the scaffolds without antibiotic showed no antimicrobial effects, the scaffold containing $1 \%(w / v)$ ECM powder did show a detectable antimicrobial effect with a clear zone of inhibition around the scaffold. When loaded with antibiotic, all the scaffold combinations produced clear zones of inhibition. Compared to the minocycline control antibiotic sensitivity discs, all the minocycline-loaded chitosan:ECM combinations produced similar zones of inhibition except for the $1 \%$ and $10 \%$ ECM where the zones of inhibition were smaller. In the $10 \%$ ECM scaffolds the zone of inhibition was $20 \%$ smaller than the control. In contrast, the rifampicin-loaded ECM scaffolds all showed smaller zones of inhibition compared to the control discs except for the 80:20 and 50:50 chitosan:ECM combinations. The smallest zones of inhibition were again in the $10 \%$ ECM scaffold group which were $21 \%$ smaller than the controls. In comparison, the 50:50 chitosan:ECM scaffold showed a $6 \%$ increase in the zone of inhibition compared to controls.

\subsubsection{Direct Antimicrobial Effects on E. COLI Bacteria}

The antimicrobial effects of the chitosan:ECM scaffolds on E. Coli were similar to that with Staph. Aureus (Figure 2F). With this bacterium, the scaffolds without antibiotic showed no antimicrobial effects. When loaded with minocycline the chitosan:ECM combinations all showed equal or larger zones 
of inhibition compared to the control except for the 10\% ECM scaffold where the zone of inhibition was $15.9 \%$ smaller than the control. While in general the E. Coli bacteria showed resistance to the rifampicin antibiotic, differences with the chitosan:ECM scaffolds could still be seen. While the 80:20, 50:50 chitosan:ECM and 1\% powdered ECM scaffolds showed similar inhibition to the control disc, the $100 \%$ chitosan and $10 \%$ powdered ECM scaffolds showed reduced zones of inhibition of $19 \%$ and $25 \%$, respectively.

\subsection{Duration of Antimicrobial Effects}

Duration of the antimicrobial effects of the different chitosan:ECM scaffold formulations was first tested using the agar well diffusion assay, which showed notable differences in the response of the two different bacterial strains to the scaffold supernatants (Figure 3). Chitosan:ECM scaffolds without antibiotic showed no ability to inhibit bacterial growth (data not shown), except for a $\sim 11 \mathrm{~mm}$ diameter zone of inhibition seen in Staph. Aureus bacteria exposed to $1 \mathrm{~h}$ supernatant samples of scaffolds $1 \%$ $(w / v)$ ECM powder.
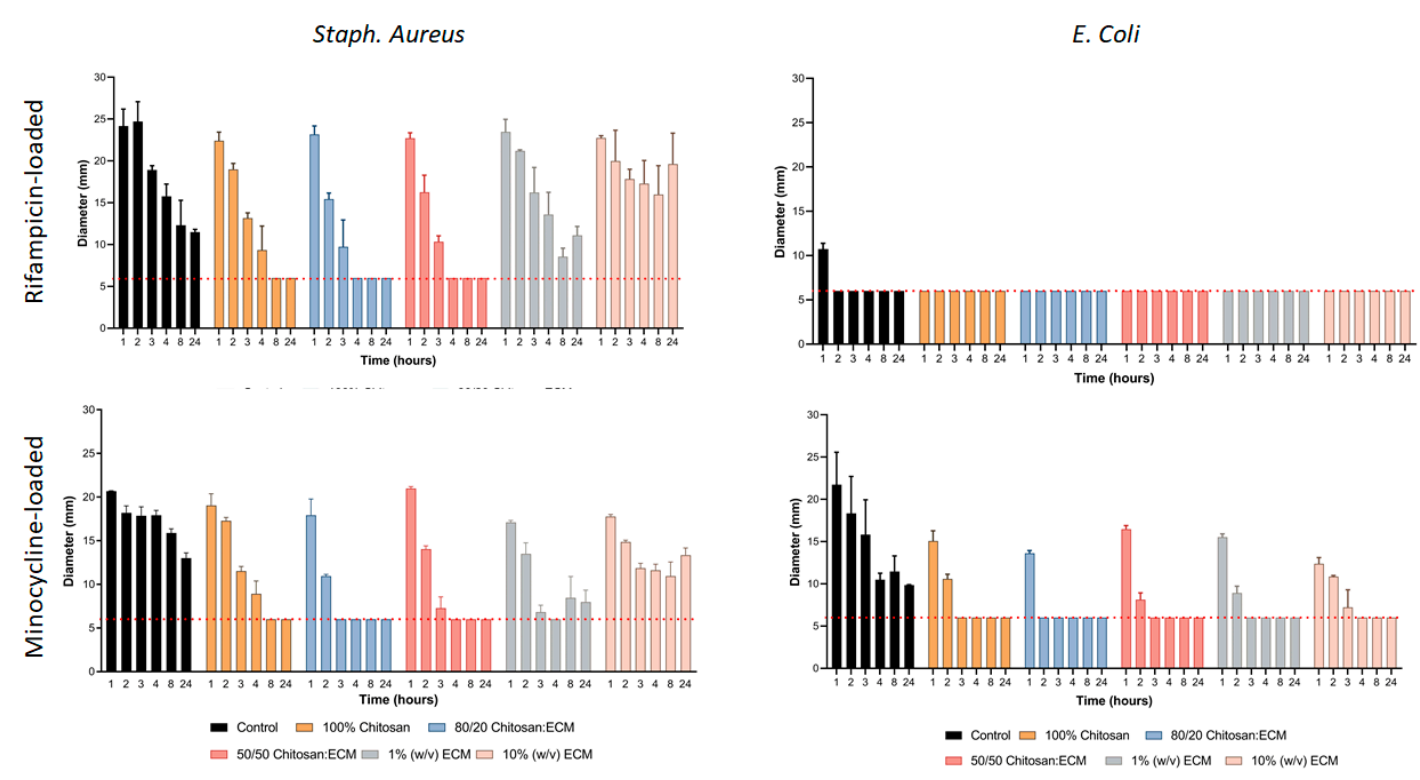

Figure 3. Graphs showing the duration of antimicrobial effects. Supernatant samples from the different scaffold formulations were taken at 1, 2, 3, 4, 8, and $24 \mathrm{~h}$ and incubated using a punch plate agar assay. Zones of inhibition were measure for both Staph. Aureus and E. Coli bacteria.

\subsubsection{Duration of Antimicrobial Effect Against Staph. Aureus}

When Staph. Aureus was exposed to supernatants from rifampicin-loaded chitosan:ECM scaffolds or control discs (Figure 3), no differences between scaffolds and control at $1 \mathrm{~h}$ were seen. All the chitosan:ECM formulations showed smaller zones of inhibition at $2 \mathrm{~h}$, except for the $1 \%(w / v)$ ECM scaffolds. Zones of inhibition were smaller for 100\% chitosan, 80/20 and 50/50 chitosan:ECM scaffolds at all subsequent time points with the ability to inhibit bacterial growth diminishing completely between 4 and $8 \mathrm{~h}$. The $1 \%$ and $10 \%(w / v)$ ECM scaffolds all retained antimicrobial activity up to $24 \mathrm{~h}$. The $1 \%$ $(w / v)$ ECM scaffolds showed no difference to controls except at $8 \mathrm{~h}$. The $10 \%(w / v)$ scaffolds showed no difference to controls except at $24 \mathrm{~h}$ where the zone of inhibition was larger than the control.

A similar response pattern was seen when Staph. Aureus was exposed to supernatants from minocycline-loaded chitosan:ECM scaffolds (Figure 3). The $1 \mathrm{~h}$ samples all showed no difference in the diameter of the zone of inhibition compared to control except for the $1 \%(w / v)$ ECM which was smaller. At $2 \mathrm{~h}$ the 80/20, 50/50 chitosan:ECM scaffolds and 1\% (w/v) ECM scaffolds had significantly smaller zones of inhibition compared to control. All the chitosan:ECM formulations had smaller zones 
of inhibition at all subsequent time points up to $24 \mathrm{~h}$. Again, the antimicrobial effect of the 80/20 and 50/50 chitosan:ECM scaffolds was lost between 2 and $3 \mathrm{~h}$ and after $4 \mathrm{~h}$ in the $100 \%$ chitosan:ECM scaffolds. The $1 \%(w / v)$ ECM scaffolds showed some antimicrobial activity up to $24 \mathrm{~h}$ but this was not as pronounced as in the controls. The $10 \%(w / v)$ ECM scaffolds had the longest duration antimicrobial activity and, although the zone of inhibition were smaller than the control, the zone of inhibition remained a consistent size at each time point and was no different to the control at $24 \mathrm{~h}$ suggesting that the scaffolds containing powdered ECM had a more prolonged the release of the antibiotic from the scaffold compared to the scaffolds made from chitosan and ECM hydrogel.

\subsubsection{Duration of Antimicrobial Effect Against E. Coli}

No zones of inhibition were seen when $E$. Coli were exposed to supernatants from rifampicin-loaded chitosan:ECM scaffolds or control discs (Figure 3), except for the $1 \mathrm{~h}$ supernatant for the control antibiotic disc. The lack of inhibition was expected given the resistance to rifampicin when the direct antimicrobial effects were tested.

Minocycline-loaded chitosan:ECM scaffolds showed clear zones of inhibition in all the scaffold groups at $1 \mathrm{~h}$, but the effect quickly diminished (Figure 3). At all the timepoints tested, the chitosan:ECM scaffolds were less effective at inhibiting $E$. Coli growth than the antibiotic control disc supernatants. In addition, while the control supernatants still had antibiotic concentrations capable of inhibiting $E$. Coli growth up to $24 \mathrm{~h}$, in the chitosan:ECM scaffolds inhibition of growth was only seen up to $2 \mathrm{~h}$ for $100 \%$ chitosan, 50/50 chitosan:ECM and 1\% (w/v) ECM scaffolds and up to $3 \mathrm{~h}$ in the 10\% (w/v) ECM scaffolds. The 80/20 chitosan:ECM scaffolds were only effective at inhibiting growth for the first $1 \mathrm{~h}$.

\subsection{Growth Kinetics Assays}

Growth kinetic assays were performed with E. Coli and Staph. Aureus exposed to the same supernatant samples from the chitosan:ECM scaffold formulations to investigate the duration of antimicrobial activity further. The growth rate of the bacteria was calculated to determine the effectiveness of the antibiotic-loaded scaffolds (Figure 4). Scaffold formulations without antibiotics were tested to determine if the chitosan:ECM formulations had any inherent antimicrobial activity. When $E$. Coli were exposed to the supernatants from the scaffolds no antimicrobial effects were seen, all samples tested resulted in the characteristic bacterial growth curve with a lag time to reach exponential growth of between 1 and $1.67 \mathrm{~h}$. No significant differences were seen between the different scaffold materials or between the different supernatant samples (Figure 4A). Interestingly, when the same supernatant samples were applied to Staph. Aureus bacteria some antimicrobial activity was seen (Figure 4B). In the 1-h supernatant samples the 100\% chitosan, 80/20 chitosan:ECM and 1\% (w/v) ECM scaffolds all reduced the growth rate of the bacteria. Bacterial growth was not completely inhibited, but the growth rate was reduced and never reached the exponential phase over the $18 \mathrm{~h}$ of the test. These results suggest that these formulations may have a bacteriostatic effect inhibiting growth but not killing the bacteria. The 50/50 chitosan:ECM and 10\% (w/v) ECM scaffolds at this timepoint did not inhibit bacterial growth; however, the 2-h supernatant samples from all the scaffold formulations reduced bacterial growth and prevented exponential growth phase. At three hours the 50/50 chitosan:ECM and $1 \%$ and $10 \%(w / v)$ ECM scaffolds continued to show reduced bacterial growth, however the $1 \%$ chitosan and 80/20 chitosan:ECM supernatants no longer inhibited bacterial growth. Moreover, the 100\% chitosan and 80/20 chitosan:ECM supernatant samples between 1 and 4 h showed gradual increase in bacterial growth suggesting that any antimicrobial molecules release by the scaffolds had completed eluted by $4 \mathrm{~h}$. All the scaffold formulations had lost their antimicrobial effect by $4 \mathrm{~h}$ with no differences in bacterial growth being seen between the different scaffolds or between different supernatant samples between hours 4 and 24 . 
E. Coli
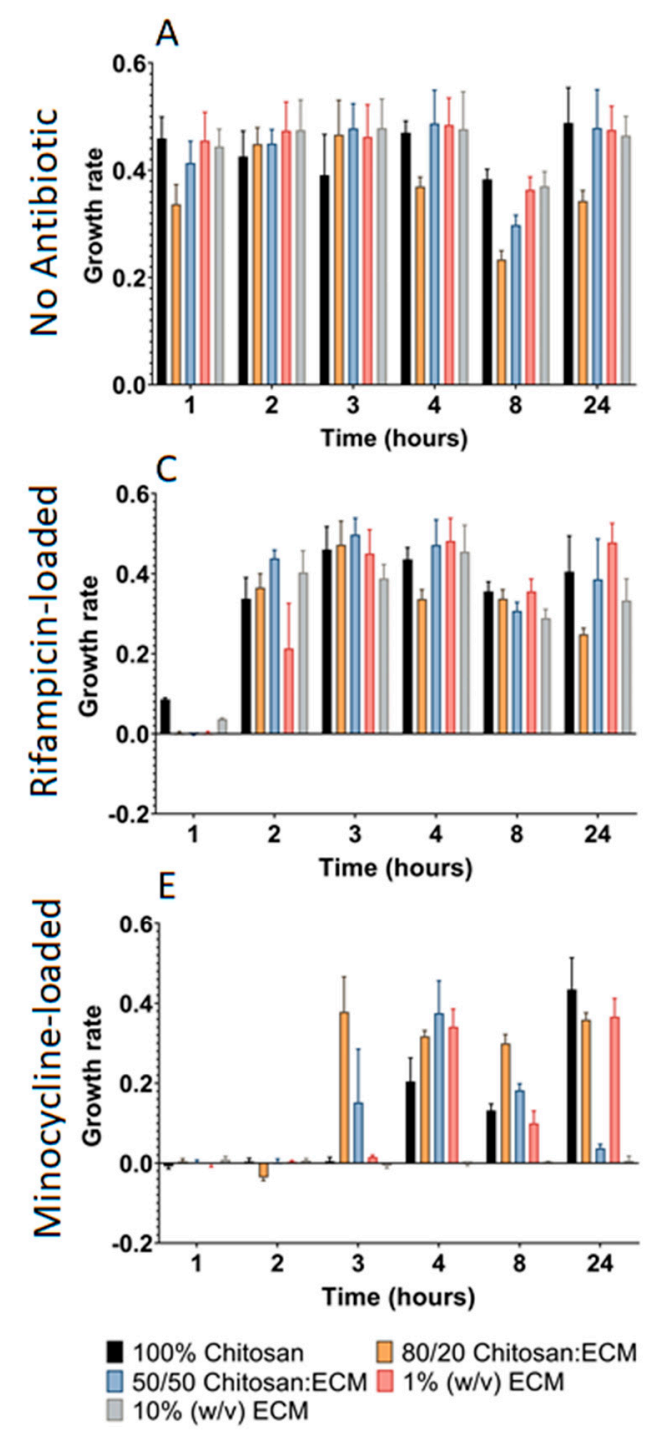

Staph. Aureus
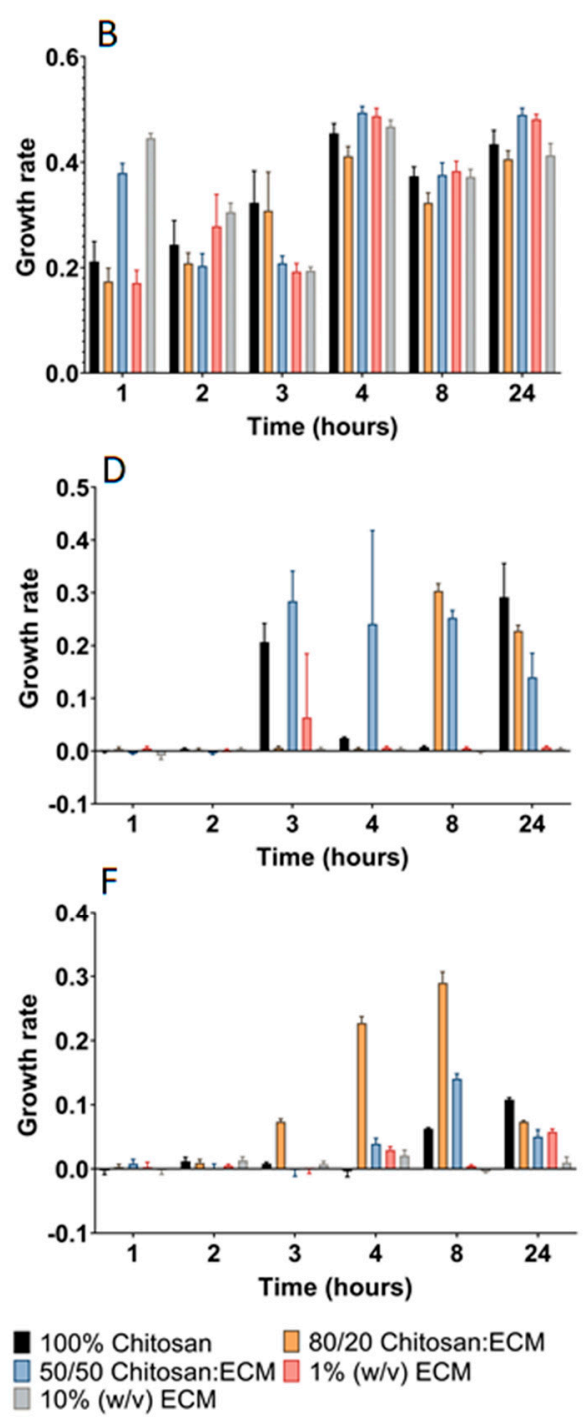

Figure 4. Graphs showing the calculated growth rate of E. Coli $(\mathbf{A}, \mathbf{C}, \mathbf{E})$ and Staph. Aureus $(\mathbf{B}, \mathbf{D}, \mathbf{F})$ bacteria exposed to different scaffold formulation supernatants. (A,B) growth rate of $E$. Coli $(\mathbf{A})$ and Staph. Aureus bacteria when exposed to supernatant samples from scaffold formulations without antibiotics; (C,D) growth rate of E. Coli (C) and Staph. Aureus (D) when exposed to supernatant samples of rifampicin-loaded scaffold formulations; $(\mathbf{E}, \mathbf{F})$ growth rate of E. Coli (E) and Staph. Aureus (F) when exposed to supernatant samples of minocycline-loaded scaffold formulations.

Supernatants from scaffolds containing antibiotic showed similar result to the agar diffusion assay, but the growth curves allowed for a more detailed analysis of the bacterial growth. When E. Coli were exposed to supernatants from rifampicin-loaded chitosan:ECM scaffolds bacterial growth was seen in all supernatant samples taken between 2- and 24-h indicative of the resistance E. Coli had to the rifampicin antibiotic (Figure 4C). However, supernatant samples taken after $1 \mathrm{~h}$ did show inhibition of growth. While the $1 \mathrm{~h}$ supernatant samples from 100\% chitosan and 10\% (w/v) ECM scaffolds showed bacterial growth, in the 10\% (w/v) ECM group this growth rate never reach the exponential phase while in the $100 \%$ chitosan group the exponential phase of growth was delayed with a lag time of $6.63 \mathrm{~h}$ compared to lag time of $1.30 \mathrm{~h}$ for the same scaffold without antibiotic. No bacterial growth was seen in the $80 / 20$ or $50 / 50$ chitosan:ECM groups or in the $1 \%(w / v)$ ECM group. 
Supernatants from minocycline-loaded chitosan:ECM scaffolds showed clear differences in the effectiveness of the scaffold formulations (Figure 4E). The supernatant samples taken at $1 \mathrm{~h}$ and $2 \mathrm{~h}$ from all the scaffold formulations completely inhibited bacterial growth and there were no differences between the different scaffold formulations. However, the supernatant samples taken at $3 \mathrm{~h}$ for the 80/20 and 50/50 chitosan:ECM formulations did not inhibit bacterial growth, and both showed exponential growth. Bacterial growth was also seen in the 1\% $(w / v)$ ECM supernatant group but this was a continuous growth that did not reach the exponential phase suggesting this scaffold formulation still had a bacteriostatic effect even though its bactericidal effects had been lost. The supernatants from the $10 \%(w / v)$ ECM group completely inhibited bacterial growth at $3 \mathrm{~h}$ and no growth was seen at any other timepoint all the way to $24 \mathrm{~h}$ indicating that this scaffold formulation continued to have a prolonged bactericidal effect and a slower release of the antibiotic than the other scaffold formulations. None of the other scaffold formulations were able to inhibit bacterial growth after $3 \mathrm{~h}$, while there were differences in the growth rates between scaffolds all the growth curves followed the typical bacterial growth curve.

Staph. Aureus exposed to supernatants from rifampicin-loaded chitosan:ECM scaffolds showed growth that was completely inhibited by supernatant samples from all the scaffolds taken at 1 and 2 h (Figure 4D). Supernatant samples taken from the 80/20 chitosan:ECM and 10\% (w/v) ECM groups at $3 \mathrm{~h}$ were still able to completely inhibit bacterial growth. The 100\% chitosan, 50/50 chitosan:ECM and $1 \%(w / v)$ ECM groups all showed bacterial growth that reached the exponential phase. However, the lag times for each scaffold were extended to $13.26,9.25$ and $11.77 \mathrm{~h}$ for each scaffold, respectively, compared to a normal lag time of between 0.56 and $1.03 \mathrm{~h}$ for the equivalent scaffolds without antibiotic. Interestingly, while the supernatant samples from $100 \%$ chitosan at $3 \mathrm{~h}$ resulted in exponential bacterial growth, samples from the same scaffold at $4 \mathrm{~h}$ and $8 \mathrm{~h}$ did not reach the exponential phase. Supernatants from the $1 \%(w / v)$ and $10 \%(w / v)$ ECM groups at 4,8 and $24 \mathrm{~h}$ completely inhibited bacterial growth. These results suggest that in these scaffolds there may be a prolonged release of the antibiotic, or the release of other antimicrobial molecules from the scaffold as the scaffold begins to degrade. Supernatants from the 80/20 chitosan:ECM group inhibited growth at $4 \mathrm{~h}$ but did not inhibit growth at 8 or $24 \mathrm{~h}$ although the lag time before reaching exponential growth was extended to 3.60 and $4.20 \mathrm{~h}$ at 8 and $24 \mathrm{~h}$, respectively. Similarly, the 50/50 chitosan:ECM scaffolds did not inhibit bacterial growth at 4,8 or $24 \mathrm{~h}$, but the lag time to reach exponential phase was extended to $10.60,3.70$ and $4.56 \mathrm{~h}$ at each timepoint, respectively. This extension of the lag phase is probably indicative of the fact that a population of the Staph. Aureus clinical isolate was resistant to rifampicin, as demonstrated on the bacterial growth plates and this population of bacteria was able to proliferate while the rifampicin-sensitive population was killed.

Growth of Staph. Aureus was completely inhibited by supernatants from minocycline-loaded chitosan:ECM scaffolds taken at 1 and $2 \mathrm{~h}$ (Figure $4 \mathrm{~F}$ ). Supernatant samples taken at $3 \mathrm{~h}$ from all the scaffolds except the 80/20 chitosan:ECM group were able to completely inhibit growth. The 80/20 chitosan:ECM group did show bacterial growth, but this failed to reach the exponential phase. Exponential bacterial growth was subsequently seen with supernatant samples from the 80/20 chitosan:ECM group at all the remaining time points except $24 \mathrm{~h}$ where the growth rate did not become exponential. Bacterial growth continued to be inhibited by the minocycline-loaded $100 \%$ chitosan group after $4 \mathrm{~h}$ while the antibiotic-loaded 50/50 chitosan:ECM, 1\% and 10\% (w/v) ECM groups all showed some bacterial growth that did not reach the exponential phase. Supernatant samples taken at $8 \mathrm{~h}$, apart for the previously discussed 80/20 chitosan:ECM group, all showed bacterial growth that was significant but did not become exponential except for the minocycline-loaded $10 \%(w / v)$ ECM which completely inhibited bacterial growth. This inhibition of bacterial growth in the antibiotic-loaded $10 \%$ $(w / v)$ ECM scaffold group continued at $24 \mathrm{~h}$ while all the other scaffold groups showed bacterial growth that did not reach the exponential phase. This again suggests that the $10 \%(w / v)$ ECM formulation prolonged the release of the antibiotic from the material while the biphasic growth seen in the other 
scaffold formulations may suggest that other antimicrobial molecules, that Staph. Aureus are more sensitive to than E. Coli, are being released as the ECM scaffolds degrade.

\subsection{Direct Cytotoxicity Testing}

Direct cytotoxicity testing was performed to determine whether the scaffold materials were cytotoxic to human microvascular endothelial cells. Antibiotic-loaded and nonantibiotic-loaded scaffolds were tested and compared to the negative and positive controls. Scaffolds were considered to have a cytotoxic effect if ANOVA showed no difference to the negative control and a significant difference to the positive control. The results of the neutral red uptake are shown in Figure 5.

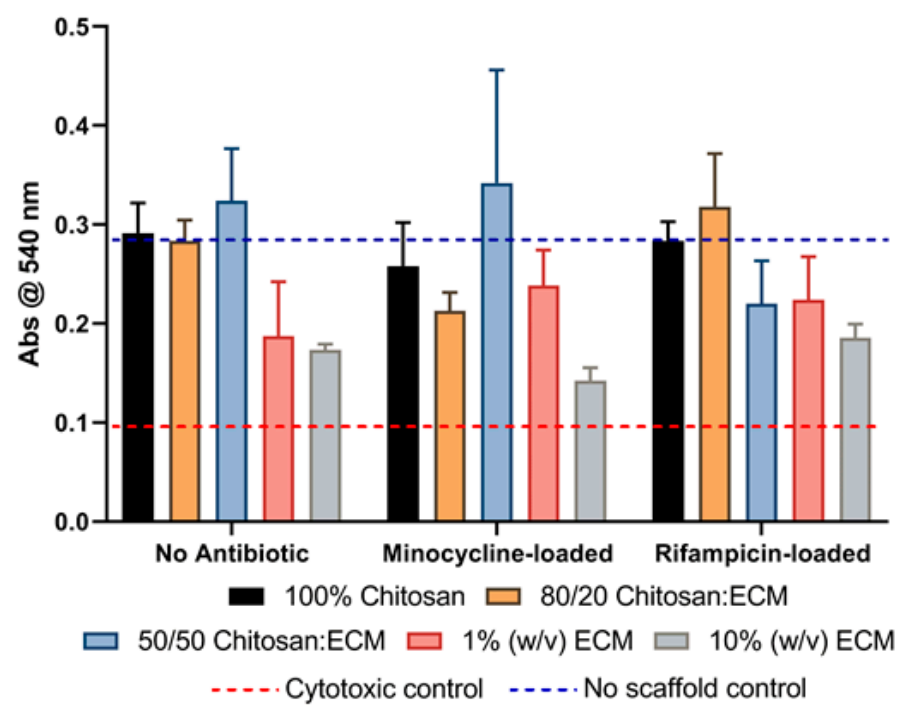

Figure 5. Graph showing the neutral red uptake by human microvascular endothelial cells exposed directly to the different scaffold formulations with and without antibiotics. Red line indicates the average neutral red uptake of cells exposed to ISO standard cytotoxic control, while the blue line shows the level of neutral red uptake in cells grown without scaffold exposure.

All the scaffold formulations without antibiotic showed no difference in neutral red uptake compared to the positive control except for the 10\% (w/v) ECM scaffolds. Significant differences were seen in all the scaffold formulations when compared to the negative control, except for the $1 \%$ and $10 \%$ $(w / v)$ ECM scaffolds that showed no differences. These results indicate that the $10 \%(w / v)$ ECM scaffold was having a cytotoxic effect on the human microvascular endothelial cells while the $1 \%(w / v)$ ECM may be reducing cell viability.

Assessment of minocycline-loaded scaffolds showed that all the scaffold formulations were different to the negative control except for the $10 \%(w / v)$ ECM and, compared to the positive control, only the $10 \%(w / v)$ ECM scaffold showed a difference. This result would again indicate that the $10 \%(w / v)$ scaffold formulation had a direct cytotoxic effect on the cells. Interestingly, assessment of rifampicin-loaded scaffolds showed that cells exposed to the $10 \%(w / v)$ ECM again had the lowest uptake of neutral red. However, none of the formulations were different to the positive, no scaffold control, and all the formulation were different to the negative control.

\subsection{Indirect Cytotoxicity Testing}

The potential cytotoxic effects of the scaffold formulations were further elucidated using indirect cytotoxicity testing. Using culture media supernatants taken from scaffold samples after 1, 2, 3, 4, 8 and $24 \mathrm{~h}$ would determine whether components eluted from the scaffolds had a cytotoxic effect. These supernatant samples represented the total eluted molecules after each time point. The neutral red uptake results for the scaffolds alone and for each antibiotic-loaded group are shown in Figure 6. 

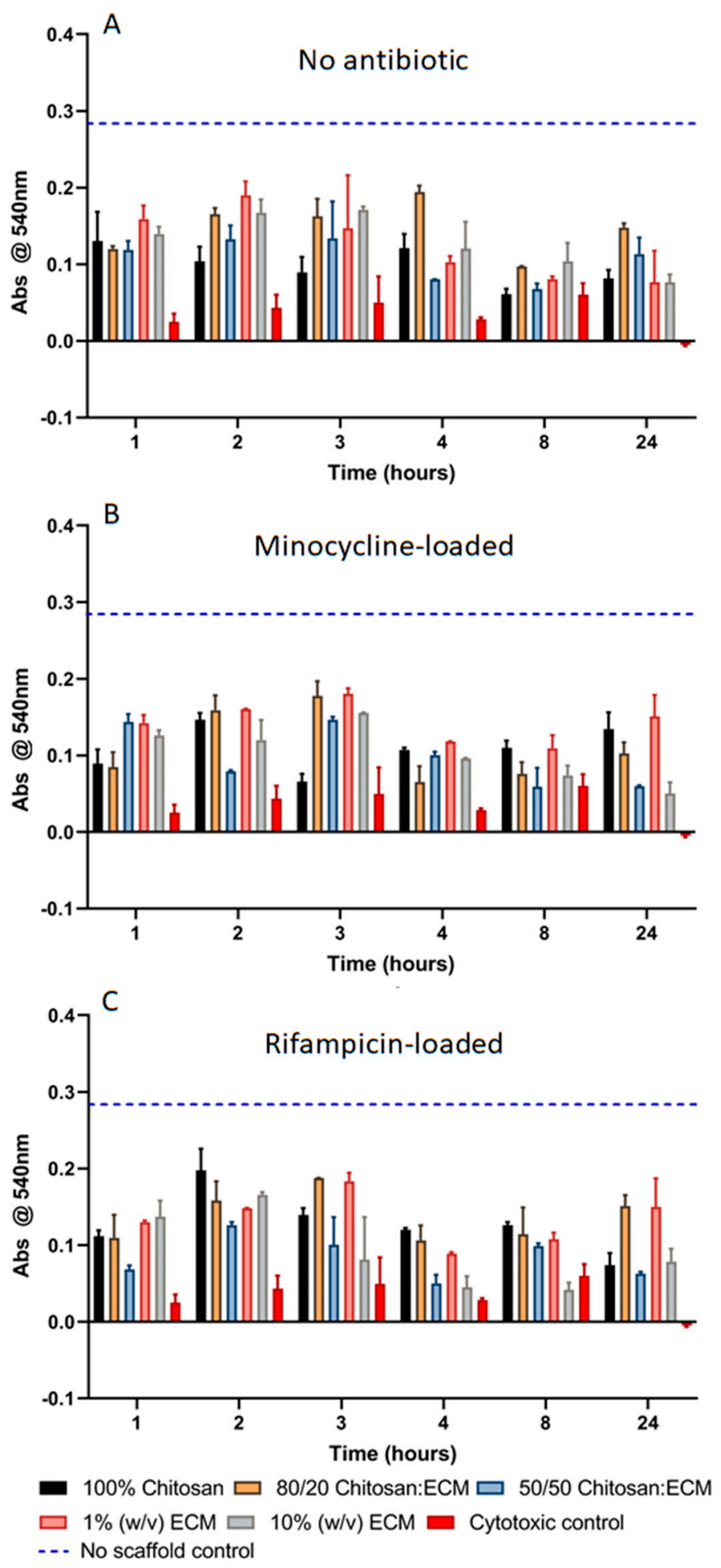

Figure 6. Graph showing the neutral red uptake by human microvascular endothelial cells exposed to supernatant samples from scaffold formulations with and without antibiotics. Supernatant samples were collected at 1, 2, 3, 4, 8 and $24 \mathrm{~h}$. (A) Neutral red uptake of cells exposed to supernatant samples from scaffold formulations without antibiotic; (B) neutral red uptake of cells exposed to supernatant samples from scaffold formulations loaded with minocycline; (C) neutral red uptake of cells exposed to supernatant samples from scaffold formulations loaded with rifampicin. Blue line shows neutral red uptake of cells cultured in culture media alone (no scaffold control). 
Supernatant samples from all the scaffold formulations, regardless of the presence or absence of antibiotic, showed reduced neutral red uptake compared to the no scaffold control at all the time points tested, only the $80 / 20$ chitosan:ECM supernatant at $4 \mathrm{~h}$ and the rifampicin-loaded $100 \%$ chitosan scaffold supernatant at $2 \mathrm{~h}$ showed similar uptake to the positive control. These results suggest that molecules eluted from these scaffolds did have the ability to inhibit cells growth. Comparison with the negative control would subsequently identify those samples that had a measurable cytotoxic effect on the cells.

Supernatant samples from the scaffolds without antibiotic (Figure 6A) showed that neutral red uptake from cells exposed to the eluted products from the $100 \%$ chitosan scaffolds was no different to the negative control at any time point, indicative of a cytotoxic effect. Cytotoxic effects were also seen with the other scaffold formulations, but the effect varied depending of the time point sampled. For example, the eluted molecules in the supernatant samples from $1 \%$ and $10 \%(w / v)$ ECM scaffolds did not become cytotoxic to the microvascular endothelial cells until $4 \mathrm{~h}$, while the 80/20 and 50/50 chitosan:ECM scaffolds were more variable with some time points showing a difference to the negative control and others showing no difference. The results suggest that while cell growth was inhibited, the cytotoxic effects may be borderline and affected by the variability of the neutral red uptake by the negative control cells.

Supernatant samples from the scaffolds loaded with minocycline (Figure 6B) again showed that neutral red uptake from cells exposed to the eluted products from the $100 \%$ chitosan scaffolds was no different to the negative control at any time point except at $24 \mathrm{~h}$. In addition, eluted molecules from the minocycline-loaded 1\% $(w / v)$ ECM again showed no cytotoxic effects until hour 4 . The minocycline-loaded 50/50 chitosan:ECM scaffolds and the 10\% (w/v) ECM scaffolds showed reduced cell growth but no cytotoxicity at hour 1 , whereas the supernatants had a cytotoxic effect at all other time points. In contrast, the 80/20 chitosan:ECM scaffolds were more variable and alternated between cytotoxic at hours 1, 4, 8 and 24 and not cytotoxic at hours 2 and 3, although these still had reduced neutral red uptake compared to the positive samples.

Supernatant samples from scaffolds loaded with rifampicin (Figure 6C) showed a similar pattern to the minocycline-loaded scaffold results. The supernatants from the 50/50 chitosan:ECM scaffolds were all classified as cytotoxic at all time points, while the $100 \%$ chitosan samples showed cytotoxicity at every time point except $2 \mathrm{~h}$. The other scaffold formulations were more variable. The $10 \%(w / v)$ scaffold supernatants showed reduced neutral red uptake but not cytotoxicity at hours 1 and 2 but were cytotoxic at all subsequent time points. The $1 \%(w / v)$ scaffold supernatants alternated between having reduced neutral red uptake but not true cytotoxicity at hours 1, 3 and 24 to being cytotoxic at hours 2, 4 and 8. Similarly, the 80/20 chitosan:ECM scaffolds at 2, 3 and $24 \mathrm{~h}$ had reduced neutral red uptake but only the supernatants from 1,4 , and $8 \mathrm{~h}$ showed no difference to the negative controls.

Overall, the results of the cytotoxicity testing indicated that all the scaffold formulations could reduce neutral red uptake by the microvascular endothelial cells directly and could reduce uptake to a level that would be classified as cytotoxic. However, it did not appear that the elution of the antibiotic from the scaffold into the culture medium had a significant indirect cytotoxic effect since no differences between the antibiotic-loaded scaffolds and the nonantibiotic-loaded scaffolds were seen.

\section{Discussion}

The textbook description of wound healing presents the process as a series of overlapping stages including hemostasis, re-epithelialization, inflammation and the formation of granulation tissue and finally remodeling. However, the healing of traumatic injuries is never this simple and the process of wound healing can be delayed by factors such as excessive bleeding, bacterial and foreign object contamination. Wound dressings aim to promote hemostasis, and ideally possess antimicrobial properties and factors to promote wound healing. The development of a multifunctional wound dressing has been a goal in trauma care for several years, particularly for tactical combat casualty care (TCCC) in the armed forces. Uncontrolled hemorrhage remains the leading cause of trauma deaths in 
both the combat and civilian settings accounting for $60 \%$ of preventable combat death [30,31]. Moreover, there is a growing incidence of bacterial wound infection, particularly in combat injuries [32-34], that is stimulating the development of new wound treatments. The dressing developed in the present study was built on a platform that utilizes two different extracellular matrices (ECM): ECM from decellularized mammalian tissue and ECM (chitosan) from crustaceans. These were chosen since both types of ECM have well established clinical benefits in promoting wound healing and controlling hemostasis. This hybrid ECM platform was augmented with the addition of antibiotics, aimed to boost bactericidal activity at the wound site.

The use of chitosan as a wound dressing is well established with a number of groups using it as a wound dressing on its own or in combination with other polymers, proteins or proteoglycans [35-44]. Similarly, ECM from decellularized mammalian tissue is already used in the manufacture of several wound dressing products [45-47]. While these decellularized tissue scaffolds are primarily used to promote rapid wound healing and constructive tissue remodeling, previous studies have shown that the degradation products of these materials have direct antimicrobial effects [48] and indirect antimicrobial effects through regulation of the inflammatory response $[49,50]$. Chitosan has also been shown to have antimicrobial properties, although, this may be dependent on the preparation method and $\mathrm{pH}$ with poor solubility of chitosan and the loss of the cationic charge in neutral and alkaline environments being two of the major obstacles to its antimicrobial activity $[25,26,51]$. Since the scaffolds used in the present study were prepared in a neutral environment and used either pepsin-digested mammalian ECM or comminuted powder, it was of interest to see if these materials without antibiotic augmentation possessed any antimicrobial activity. Interestingly, under certain circumstances, the scaffolds alone did have antimicrobial activity against Staph. Aureus bacteria, but not E. Coli. Looking at the zone of inhibition around the different scaffold formulations all the scaffolds, the scaffolds made from $100 \%$ chitosan or the 80/20 and 50/50 chitosan ECM hydrogel mix showed a small zone of inhibition around the scaffold that was only $1 \mathrm{~mm}$ larger than the scaffold disc at most. Only the $1 \%(w / v)$ scaffolds produced a clear, consistent zone of inhibition that was over $4 \mathrm{~mm}$ larger than the scaffold discs. Similarly, when the growth rates of Staph. Aureus were compared after exposure to the scaffold supernatants, some degree of bacteriostatic effect was seen with supernatant samples from incubations up to $3 \mathrm{~h}$ where all the scaffold formulations were able to reduce, but not completely inhibit, bacterial growth.

The inclusion of antibiotics into the scaffold formulations had an obvious effect on the antimicrobial properties of the scaffolds. The two antibiotics, minocycline and rifampicin, were chosen because these were antibiotics already approved to the use in topical wound dressings and the dosage was matched to that used in antibiotic sensitivity discs to allow easy comparison to a representative control. Consequently, this proof of principle experiment did not attempt to optimize the antibiotic concentration and it is possible that some of the results of the antimicrobial and cytotoxicity tests would have been different had an optimal dose been used. The clinical isolates of bacteria that were used in this study also had different sensitivities to the antibiotic. Both E. Coli and Staph. Aureus showed resistance to the rifampicin antibiotic, but in the case of Staph. Aureus, it was only a specific subpopulation of bacteria that were resistant. The presence of these resistant strains explains the growth rate results seen with the scaffold supernatants. In these studies, the antibiotic was effective at killing the rifampicin-sensitive bacteria but allowed the resistant strain to survive and eventually proliferate at an exponential rate resulting in the long lag times of 10-13 h that were seen. Other groups have shown that chitosan scaffolds can be loaded with other antibiotics with similar results to the present study. Fazli and Shariatini prepared chitosan-polyethylene oxide scaffolds that were loaded with cefazolin and cefazolin-loaded silica nanoparticles [52]. They showed that the antibiotic was released from the scaffolds easily and that they were $100 \%$ effective against Staph. Aureus and E. Coli in vitro. Mi et al. used a chitosan scaffold as a delivery vehicle for silver sulfadiazine which showed similar release profiles to the scaffolds in the present study by had antimicrobial effectiveness up to 1 week and was successful at inhibiting Pseudomonas Aeruginosa and Staph. Aureus infection in 
wounds in vivo [53]. Tennent et al. used chitosan sponges to deliver a combination of vancomycin and tobramycin, testing the effectiveness using bioluminescent strains Staph. Aureus and P. Aeruginosa in a large animal model. While the wound healing properties of the scaffolds were not investigated, they showed that the antibiotic-loaded scaffolds effectively reduced, but did not completely eliminate, the bacterial infection, while unloaded scaffolds allowed the bacteria to grow and proliferate [54].

Interestingly, the incorporation of mammalian ECM, whether in hydrogel form or particulates, appeared to alter the effectiveness and release rate of the antibiotics. $1 \%(w / v)$ and $10 \%(w / v)$ ECM scaffolds had a sustained release of minocycline and rifampicin that was effective at inhibiting bacterial growth for up to $24 \mathrm{~h}$, while the 100\% chitosan, 80/20, and 50/50 chitosan:ECM scaffolds released the antibiotic faster and lost their effectiveness typically after around $3 \mathrm{~h}$. Moreover, when looking at the effect of minocycline-loaded scaffolds on $E$. Coli, while the antibiotic sensitivity discs inhibited bacterial growth of up to $24 \mathrm{~h}$, all the scaffold formulations lost their original effectiveness after approximately $2-3 \mathrm{~h}$ suggesting that the effectiveness of the antibiotic was being altered by the material properties of the scaffolds. Antibiotic release by the scaffolds was expected to be by passive diffusion and so prolonged release of the antibiotic promoted by the presence of ECM is not thought to be the result of direct protein interaction between the ECM and the antibiotics. However, this interaction was not investigated. The more likely explanation is that the presence of ECM increases the ability of the scaffolds to retain water since the hydrated ECM is approximately $90 \%$ water, resulting in slower diffusion of the antibiotic out of the scaffold material. Modulating the release profile of the antibiotics could be modified further in a number of ways. Chemical cross-linking of the scaffold materials would prevent degradation of the material potentially prolonging antibiotic release. However, cross-linking would reduce the constructive remodeling properties of the ECM scaffolds $[55,56]$. An alternative approach would be to encapsulate the antibiotic in some form of microsphere. Chitosan microspheres have been developed to provide a variety of controlled-release molecules including antimicrobial chemicals [57-60]. These microspheres could easily be incorporated into the current scaffold design to provide prolonged antibiotic release, or even incorporation of a secondary antibiotic or wound healing factor to further promote wound healing.

The antimicrobial effectiveness of the scaffolds is of little consequence if the scaffold formulations prove to be cytotoxic. Two tests for cytotoxicity were performed flowing ISO standards to test the direct and indirect cytotoxic properties of the scaffolds. Chitosan and mammalian ECM were not expected to be cytotoxic, although some studies have shown that these materials, or their structural composition, can affect cell growth, proliferation and cell infiltration. Under certain conditions and preparation methods, chitosan has been shown to support poor cell growth with cells remaining rounded and clumping together [61,62]. While mammalian ECM contains components that promote cell attachment, dense ECM scaffold materials such as multilaminated scaffolds, can slow cellular growth and inhibit cellular infiltration $[56,63,64]$. The neutral red uptake assay is designed to test cytotoxicity independently of the ability of the scaffolds to support cell growth as the scaffold materials are applied to the cells, rather than vice versa as is more commonly done. Interestingly, the $1 \%(w / v)$ and $10 \%(w / v)$ ECM formulations showed reduced cell viability with or without antibiotic loading, with the $10 \%(w / v)$ ECM scaffold meeting the criteria for being classified cytotoxic. Since ECM is not known to be cytotoxic, this was an unexpected result and one that requires further analysis. Endotoxin testing of the chitosan component of the scaffolds showed that the starting solution ( $100 \%$ chitosan) contained approximately $5 \mathrm{EU} / \mathrm{mL}$ (approximately $0.5 \mathrm{mg} / \mathrm{mL}$ ). Since endotoxin activity depends on a variety of factors such as polysaccharide chain length, solubility and source, the possibility that endotoxin is the cause of the cytotoxicity cannot be ruled out. Studies of the effects of endotoxin generally use much higher endotoxin levels than those found in the present study, typically using levels in the microgram rather than nanogram range. Nalbantsoy et al. showed that $100 \mathrm{ug} / \mathrm{mL}$ were capable of altering the morphology and could reduce the proliferation rate of hybridoma cells by $62 \%$ [65]. Unger et al. have compared the LAL endotoxin assay to a cell-based assay using microvascular endothelial cells. While they did not specifically look at viability of the cells, they did show that microvascular endothelial cells 
were particularly sensitive to endotoxin, resulting in significant changes in e-selectin expression [66]. The neutral red uptake assay does have a high sensitivity that may lead to false positive results and the experiment must be carefully controlled using known standards for cytotoxicity. It is a possibility that since this scaffold formulation was shown to swell and lose integrity when hydrated, cell attachment to the scaffold or sloughing of the cell monolayer during scaffold removal may have occurred, reducing the cell density and therefore reducing neutral red uptake relative to the other materials. Specific cell attachment assays would help to understand this result and will be performed in the future. While the direct cytotoxicity assays showed that only the two scaffold formulations containing particulate ECM reduced neutral red uptake, the indirect cytotoxicity assays showed that neutral red uptake was reduced by all the supernatant samples of all the scaffold formulations. The presence of the antibiotics did not significantly change the cellular response to the scaffold supernatants suggesting that the antibiotics themselves were not cytotoxic but rather something in either the chitosan or ECM that was having the effect. Again, this response to the ECM material was a surprising result since both these materials are considered biocompatible in several applications and are approved for use in wound dressings without adverse reactions $[13,47,67,68]$. Studies looking at endotoxin burden of ECM-based scaffolds have shown that while endotoxin definitely influences the short-term host response to these materials, the long-term constructive remodeling effects were unchanged [69]. It is possible that the sensitivity of the neutral red assay was influenced by the endotoxin content of the scaffolds, but it remains to be seen if this would alter the long-term success of the scaffold materials in vivo. It is also possible that serum proteins within the media being used to prepare the supernatants could have adsorbed or bound to proteins within the scaffold [70], reducing their availability to the cells.

\section{Conclusions}

In summary, the present study has shown that hybrid dressing materials comprising chitosan and mammalian ECM can be produced and form stable, useable dressing materials. The use of ECM hydrogel versus particulate ECM results in clear differences in the scaffold handling properties, scaffold integrity over time and in the effectiveness and release rate of loaded antibiotics. Moreover, antibiotics directly mixed with the chitosan:ECM mixture are easily released from the scaffold and remain effective for at least $2 \mathrm{~h}$ but can be extended up to $24 \mathrm{~h}$ by modifying the scaffold composition. Variable results with cytotoxicity testing show that further work is required to optimize the scaffold formulations and direct cell culture of the cells on the scaffolds is necessary to validate the cytotoxicity results before preclinical testing. However, these early proof of principle experiments suggest that these scaffolds may have potential as viable bioactive wound dressings.

Author Contributions: Conceptualization: N.J.T.; methodology: N.J.T., S.G.; data analysis: S.G., N.J.T.; writing—original draft preparation: N.J.T.; writing—review and editing: N.J.T. All authors have read and agreed to the published version of the manuscript.

Funding: This research received no external funding.

Acknowledgments: The authors would like to thank Stephen Badylak for the provision of ECM materials and support in reviewing the manuscript and experimental design.

Conflicts of Interest: The authors declare no conflict of interest.

\section{References}

1. Tharanathan, R.N.; Kittur, F.S. Chitin-The undisputed biomolecule of great potential. Crit. Rev. Food Sci. Nutr. 2003, 43, 61-87. [CrossRef]

2. Dragostin, O.M.; Samal, S.K.; Dash, M.; Lupascu, F.; Panzariu, A.; Tuchilus, C.; Ghetu, N.; Danciu, M.; Dubruel, P.; Pieptu, D.; et al. New antimicrobial chitosan derivatives for wound dressing applications. Carbohydr. Polym. 2016, 141, 28-40. [CrossRef]

3. Samal, S.K.; Dash, M.; Chiellini, F.; Wang, X.; Chiellini, E.; Declercq, H.A.; Kaplan, D.L. Silk/chitosan biohybrid hydrogels and scaffolds via green technology. RSC Adv. 2014, 4, 53547-53556. [CrossRef] 
4. Ma, G.; Yang, D.; Zhou, Y.; Xiao, M.; Kennedy, J.F.; Nie, J. Preparation and characterization of water-soluble N-alkylated chitosan. Carbohydr. Polym. 2008, 74, 121-126. [CrossRef]

5. Martins, A.; Facchi, S.; Follmann, H.; Pereira, A.; Rubira, A.; Muniz, E. Antimicrobial activity of chitosan derivatives containing $\mathrm{N}$-quaternized moieties in its backbone: A review. Int. J. Mol. Sci. 2014, 15, 20800-20832. [CrossRef]

6. Xue, H.; Hu, L.; Xiong, Y.; Zhu, X.; Wei, C.; Cao, F.; Zhou, W.; Sun, Y.; Endo, Y.; Liu, M.; et al. Quaternized chitosan-Matrigel-polyacrylamide hydrogels as wound dressing for wound repair and regeneration. Carbohydr. Polym. 2019, 226, 115302. [CrossRef]

7. Jayakumar, R.; Prabaharan, M.; Sudheesh Kumar, P.T.; Nair, S.V.; Tamura, H. Biomaterials based on chitin and chitosan in wound dressing applications. Biotechnol. Adv. 2011, 29, 322-337. [CrossRef]

8. Dumont, M.; Villet, R.; Guirand, M.; Montembault, A.; Delair, T.; Lack, S.; Barikosky, M.; Crepet, A.; Alcouffe, P.; Laurent, F.; et al. Processing and antibacterial properties of chitosan-coated alginate fibers. Carbohydr. Polym. 2018, 190, 31-42. [CrossRef]

9. Ignatova, M.; Manolova, N.; Rashkov, I. Electrospun antibacterial chitosan-based fibers. Macromol. Biosci. 2013, 13, 860-872. [CrossRef]

10. Boonkong, W.; Petsom, A.; Thongchul, N. Rapidly stopping hemorrhage by enhancing blood clotting at an opened wound using chitosan/polylactic acid/polycaprolactone wound dressing device. J. Mater. Sci. Mater. Med. 2013, 24, 1581-1593. [CrossRef]

11. Pusateri, A.E.; McCarthy, S.J.; Gregory, K.W.; Harris, R.A.; Cardenas, L.; McManus, A.T.; Goodwin, C.W., Jr. Effect of a chitosan-based hemostatic dressing on blood loss and survival in a model of severe venous hemorrhage and hepatic injury in swine. J. Trauma 2003, 54, 177-182. [CrossRef] [PubMed]

12. Yang, J.; Tian, F.; Wang, Z.; Wang, Q.; Zeng, Y.J.; Chen, S.Q. Effect of chitosan molecular weight and deacetylation degree on hemostasis. J. Biomed. Mater. Res. B Appl. Biomater. 2008, 84, 131-137. [CrossRef] [PubMed]

13. Kozen, B.G.; Kircher, S.J.; Henao, J.; Godinez, F.S.; Johnson, A.S. An alternative hemostatic dressing: Comparison of CELOX, HemCon, and QuikClot. Acad. Emerg. Med. 2008, 15, 74-81. [CrossRef] [PubMed]

14. Pozza, M.; Millner, R.W. Celox (chitosan) for haemostasis in massive traumatic bleeding: Experience in Afghanistan. Eur. J. Emerg. Med. 2011, 18, 31-33. [CrossRef]

15. Chang, S.H.; Lin, Y.Y.; Wu, G.J.; Huang, C.H.; Tsai, G.J. Effect of chitosan molecular weight on anti-inflammatory activity in the RAW 264.7 macrophage model. Int. J. Biol. Macromol. 2019, 131, 167-175. [CrossRef]

16. Ueno, H.; Nakamura, F.; Murakami, M.; Okumura, M.; Kadosawa, T.; Fujinag, T. Evaluation effects of chitosan for the extracellular matrix production by fibroblasts and the growth factors production by macrophages. Biomaterials 2001, 22, 2125-2130. [CrossRef]

17. Vasconcelos, D.P.; Costa, M.; Amaral, I.F.; Barbosa, M.A.; Aguas, A.P.; Barbosa, J.N. Modulation of the inflammatory response to chitosan through M2 macrophage polarization using pro-resolution mediators. Biomaterials 2015, 37, 116-123. [CrossRef]

18. Badylak, S.F. The extracellular matrix as a biologic scaffold material. Biomaterials 2007, 28, 3587-3593. [CrossRef]

19. Agrawal, V.; Brown, B.N.; Beattie, A.J.; Gilbert, T.W.; Badylak, S.F. Evidence of innervation following extracellular matrix scaffold-mediated remodelling of muscular tissues. J. Tissue Eng. Regen. Med. 2009, 3, 590-600. [CrossRef]

20. Badylak, S.F.; Freytes, D.O.; Gilbert, T.W. Extracellular matrix as a biological scaffold material: Structure and function. Acta Biomater. 2009, 5, 1-13. [CrossRef]

21. Badylak, S.F.; Gilbert, T.W. Immune response to biologic scaffold materials. Semin. Immunol. 2008, 20, 109-116. [CrossRef] [PubMed]

22. Beattie, A.J.; Gilbert, T.W.; Guyot, J.P.; Yates, A.J.; Badylak, S.F. Chemoattraction of progenitor cells by remodeling extracellular matrix scaffolds. Tissue Eng. Part A 2009, 15, 1119-1125. [CrossRef] [PubMed]

23. Davis, G.E. Matricryptic sites control tissue injury responses in the cardiovascular system: Relationships to pattern recognition receptor regulated events. J. Mol. Cell Cardiol. 2010, 48, 454-460. [CrossRef] [PubMed]

24. Davis, G.E.; Bayless, K.J.; Davis, M.J.; Meininger, G.A. Regulation of tissue injury responses by the exposure of matricryptic sites within extracellular matrix molecules. Am. J. Pathol. 2000, 156, 1489-1498. [CrossRef] 
25. Andres, Y.; Giraud, L.; Gerente, C.; Le Cloirec, P. Antibacterial effects of chitosan powder: Mechanisms of action. Environ. Technol. 2007, 28, 1357-1363. [CrossRef]

26. Kong, M.; Chen, X.G.; Xing, K.; Park, H.J. Antimicrobial properties of chitosan and mode of action: A state of the art review. Int. J. Food Microbiol. 2010, 144, 51-63. [CrossRef]

27. Rabea, E.I.; Badawy, M.E.; Stevens, C.V.; Smagghe, G.; Steurbaut, W. Chitosan as antimicrobial agent: Applications and mode of action. Biomacromolecules 2003, 4, 1457-1465. [CrossRef]

28. Brown, B.; Lindberg, K.; Reing, J.; Stolz, D.B.; Badylak, S.F. The basement membrane component of biologic scaffolds derived from extracellular matrix. Tissue Eng. 2006, 12, 519-526. [CrossRef]

29. Freytes, D.O.; Tullius, R.S.; Valentin, J.E.; Stewart-Akers, A.M.; Badylak, S.F. Hydrated versus lyophilized forms of porcine extracellular matrix derived from the urinary bladder. J. Biomed. Mater. Res. Part A 2008, 87, 862-872. [CrossRef]

30. Gawande, A. Casualties of war-military care for the wounded from Iraq and Afghanistan. N. Engl. J. Med. 2004, 351, 2471-2475. [CrossRef]

31. Gondusky, J.S.; Reiter, M.P. Protecting military convoys in Iraq: An examination of battle injuries sustained by a mechanized battalion during Operation Iraqi Freedom II. Mil. Med. 2005, 170, 546-549. [CrossRef]

32. Murray, C.K.; Wilkins, K.; Molter, N.C.; Li, F.; Yu, L.; Spott, M.A.; Eastridge, B.; Blackbourne, L.H.; Hospenthal, D.R. Infections complicating the care of combat casualties during operations Iraqi Freedom and Enduring Freedom. J. Trauma 2011, 71, S62-S73. [CrossRef] [PubMed]

33. Murray, C.K.; Wilkins, K.; Molter, N.C.; Yun, H.C.; Dubick, M.A.; Spott, M.A.; Jenkins, D.; Eastridge, B.; Holcomb, J.B.; Blackbourne, L.H.; et al. Infections in combat casualties during Operations Iraqi and Enduring Freedom. J. Trauma 2009, 66, S138-S144. [CrossRef] [PubMed]

34. Tully, C.C.; Romanelli, A.M.; Sutton, D.A.; Wickes, B.L.; Hospenthal, D.R. Fatal Actinomucor elegans var. kuwaitiensis infection following combat trauma. J. Clin. Microbiol. 2009, 47, 3394-3399. [CrossRef] [PubMed]

35. Abdel-Rahman, R.M.; Abdel-Mohsen, A.M.; Hrdina, R.; Burgert, L.; Fohlerova, Z.; Pavlinak, D.; Sayed, O.N.; Jancar, J. Wound dressing based on chitosan/hyaluronan/nonwoven fabrics: Preparation, characterization and medical applications. Int. J. Biol. Macromol. 2016, 89, 725-736. [CrossRef]

36. Anisha, B.S.; Biswas, R.; Chennazhi, K.P.; Jayakumar, R. Chitosan-hyaluronic acid/nano silver composite sponges for drug resistant bacteria infected diabetic wounds. Int. J. Biol. Macromol. 2013, 62, 310-320. [CrossRef]

37. Arockianathan, P.M.; Sekar, S.; Kumaran, B.; Sastry, T.P. Preparation, characterization and evaluation of biocomposite films containing chitosan and sago starch impregnated with silver nanoparticles. Int. J. Biol. Macromol. 2012, 50, 939-946. [CrossRef]

38. Ehterami, A.; Salehi, M.; Farzamfar, S.; Vaez, A.; Samadian, H.; Sahrapeyma, H.; Mirzaii, M.; Ghorbani, S.; Goodarzi, A. In vitro and in vivo study of PCL/COLL wound dressing loaded with insulin-chitosan nanoparticles on cutaneous wound healing in rats model. Int. J. Biol. Macromol. 2018, 117, 601-609. [CrossRef]

39. Kenawy, E.; Omer, A.M.; Tamer, T.M.; Elmeligy, M.A.; Eldin, M.S.M. Fabrication of biodegradable gelatin/chitosan/cinnamaldehyde crosslinked membranes for antibacterial wound dressing applications. Int. J. Biol. Macromol. 2019, 139, 440-448. [CrossRef]

40. Nejaddehbashi, F.; Hashemitabar, M.; Bayati, V.; Abbaspour, M.; Moghimipour, E.; Orazizadeh, M. Application of polycaprolactone, chitosan, and collagen composite as a nanofibrous mat loaded with silver sulfadiazine and growth factors for wound dressing. Artif. Organs. 2019, 43, 413-423. [CrossRef]

41. Park, J.U.; Song, E.H.; Jeong, S.H.; Song, J.; Kim, H.E.; Kim, S. Chitosan-Based Dressing Materials for Problematic Wound Management. Adv. Exp. Med. Biol. 2018, 1077, 527-537. [CrossRef] [PubMed]

42. Vigani, B.; Rossi, S.; Sandri, G.; Bonferoni, M.C.; Caramella, C.M.; Ferrari, F. Hyaluronic acid and chitosan-based nanosystems: A new dressing generation for wound care. Expert. Opin. Drug Deliv. 2019, 16, 715-740. [CrossRef] [PubMed]

43. Wang, X.; Cheng, F.; Gao, J.; Wang, L. Antibacterial wound dressing from chitosan/polyethylene oxide nanofibers mats embedded with silver nanoparticles. J. Biomater. Appl. 2015, 29, 1086-1095. [CrossRef]

44. Zhao, W.Y.; Fang, Q.Q.; Wang, X.F.; Wang, X.W.; Zhang, T.; Shi, B.H.; Zheng, B.; Zhang, D.D.; Hu, Y.Y.; Ma, L.; et al. Chitosan-calcium alginate dressing promotes wound healing: A preliminary study. Wound Repair Regen. 2020, 28, 326-337. [CrossRef] [PubMed] 
45. Ferreras, D.T.; Craig, S.; Malcomb, R. Use of an Ovine Collagen Dressing with Intact Extracellular Matrix to Improve Wound Closure Times and Reduce Expenditures in a US Military Veteran Hospital Outpatient Wound Center. Surg. Technol. Int. 2017, 30, 61-69.

46. Kim, T.H.; Jung, Y.; Kim, S.H. Nanofibrous Electrospun Heart Decellularized Extracellular Matrix-Based Hybrid Scaffold as Wound Dressing for Reducing Scarring in Wound Healing. Tissue Eng. Part A 2018, 24, 830-848. [CrossRef]

47. Turner, N.J.; Badylak, S.F. The Use of Biologic Scaffolds in the Treatment of Chronic Nonhealing Wounds. Adv. Wound Care 2015, 4, 490-500. [CrossRef]

48. Brennan, E.P.; Reing, J.; Chew, D.; Myers-Irvin, J.M.; Young, E.J.; Badylak, S.F. Antibacterial activity within degradation products of biological scaffolds composed of extracellular matrix. Tissue Eng. 2006, 12, 2949-2955. [CrossRef]

49. Brown, B.N.; Londono, R.; Tottey, S.; Zhang, L.; Kukla, K.A.; Wolf, M.T.; Daly, K.A.; Reing, J.E.; Badylak, S.F. Macrophage phenotype as a predictor of constructive remodeling following the implantation of biologically derived surgical mesh materials. Acta Biomater. 2012, 8, 978-987. [CrossRef]

50. Dziki, J.L.; Sicari, B.M.; Wolf, M.T.; Cramer, M.C.; Badylak, S.F. Immunomodulation and Mobilization of Progenitor Cells by Extracellular Matrix Bioscaffolds for Volumetric Muscle Loss Treatment. Tissue Eng. Part A 2016, 22, 1129-1139. [CrossRef]

51. Riezk, A.; Raynes, J.G.; Yardley, V.; Murdan, S.; Croft, S.L. Activity of chitosan and its derivatives against Leishmania major and L. mexicana in vitro. Antimicrob. Agents Chemother. 2020, 64, 3. [CrossRef] [PubMed]

52. Fazli, Y.; Shariatinia, Z. Controlled release of cefazolin sodium antibiotic drug from electrospun chitosan-polyethylene oxide nanofibrous Mats. Mater. Sci. Eng. C Mater. Biol. Appl. 2017, 71, 641-652. [CrossRef] [PubMed]

53. Mi, F.L.; Wu, Y.B.; Shyu, S.S.; Schoung, J.Y.; Huang, Y.B.; Tsai, Y.H.; Hao, J.Y. Control of wound infections using a bilayer chitosan wound dressing with sustainable antibiotic delivery. J. Biomed. Mater. Res. 2002, 59, 438-449. [CrossRef] [PubMed]

54. Tennent, D.J.; Shiels, S.M.; Jennings, J.A.; Haggard, W.O.; Wenke, J.C. Local control of polymicrobial infections via a dual antibiotic delivery system. J. Orthop. Surg. Res. 2018, 13, 53. [CrossRef]

55. Liang, H.C.; Chang, Y.; Hsu, C.K.; Lee, M.H.; Sung, H.W. Effects of crosslinking degree of an acellular biological tissue on its tissue regeneration pattern. Biomaterials 2004, 25, 3541-3552. [CrossRef]

56. Valentin, J.E.; Turner, N.J.; Gilbert, T.W.; Badylak, S.F. Functional skeletal muscle formation with a biologic scaffold. Biomaterials 2010, 31, 7475-7484. [CrossRef]

57. Liang, J.; Wang, J.; Li, S.; Xu, L.; Wang, R.; Chen, R.; Sun, Y. The size-controllable preparation of chitosan/silver nanoparticle composite microsphere and its antimicrobial performance. Carbohydr. Polym. 2019, 220, $22-29$. [CrossRef] [PubMed]

58. Ma, Z.; Kim, D.; Adesogan, A.T.; Ko, S.; Galvao, K.; Jeong, K.C. Chitosan Microparticles Exert Broad-Spectrum Antimicrobial Activity against Antibiotic-Resistant Micro-organisms without Increasing Resistance. ACS Appl. Mater. Interfaces 2016, 8, 10700-10709. [CrossRef]

59. Guo, J.; Sun, X.; Yin, H.; Wang, T.; Li, Y.; Zhou, C.; Zhou, H.; He, S.; Cong, H. Chitosan Microsphere Used as an Effective System to Deliver a Linked Antigenic Peptides Vaccine Protect Mice Against Acute and Chronic Toxoplasmosis. Front. Cell. Infect. Microbiol. 2018, 8, 163. [CrossRef]

60. Majithiya, R.J.; Murthy, R.S. Chitosan-based mucoadhesive microspheres of clarithromycin as a delivery system for antibiotic to stomach. Curr. Drug Deliv. 2005, 2, 235-242. [CrossRef]

61. Amaral, I.F.; Cordeiro, A.L.; Sampaio, P.; Barbosa, M.A. Attachment, spreading and short-term proliferation of human osteoblastic cells cultured on chitosan films with different degrees of acetylation. J. Biomater. Sci. Polym. Ed. 2007, 18, 469-485. [CrossRef] [PubMed]

62. Hamilton, V.; Yuan, Y.; Rigney, D.A.; Puckett, A.D.; Ong, J.L.; Yang, Y.; Elder, S.H.; Bumgardner, J.D. Characterization of chitosan films and effects on fibroblast cell attachment and proliferation. J. Mater. Sci. Mater. Med. 2006, 17, 1373-1381. [CrossRef] [PubMed]

63. Carey, L.E.; Dearth, C.L.; Johnson, S.A.; Londono, R.; Medberry, C.J.; Daly, K.A.; Badylak, S.F. In vivo degradation of 14C-labeled porcine dermis biologic scaffold. Biomaterials 2014, 35, 8297-8304. [CrossRef] [PubMed] 
64. Costa, A.; Naranjo, J.D.; Turner, N.J.; Swinehart, I.T.; Kolich, B.D.; Shaffiey, S.A.; Londono, R.; Keane, T.J.; Reing, J.E.; Johnson, S.A.; et al. Mechanical strength vs. degradation of a biologically-derived surgical mesh over time in a rodent full thickness abdominal wall defect. Biomaterials 2016, 108, 81-90. [CrossRef]

65. Nalbantsoy, A.; Karabay-Yavasoglu, N.; Deliloglu-Gurhan, I. Determination of in vivo toxicity and in vitro cytotoxicity of lipopolysaccharide isolated from Salmonella enteritidis and its potential use for production of polyclonal antibody. Food Agric. Immunol. 2011, 22, 271-281. [CrossRef]

66. Unger, R.E.; Peters, K.; Sartoris, A.; Freese, C.; Kirkpatrick, C.J. Human endothelial cell-based assay for endotoxin as sensitive as the conventional Limulus Amebocyte Lysate assay. Biomaterials 2014, 35, 3180-3187. [CrossRef]

67. Kimmel, H.; Rahn, M.; Gilbert, T.W. The clinical effectiveness in wound healing with extracellular matrix derived from porcine urinary bladder matrix: A case series on severe chronic wounds. J. Am. Coll. Certif. Wound Spec. 2010, 2, 55-59. [CrossRef]

68. Millner, R.W.; Lockhart, A.S.; Bird, H.; Alexiou, C. A new hemostatic agent: Initial life-saving experience with Celox (chitosan) in cardiothoracic surgery. Ann. Thorac. Surg. 2009, 87, e13-e14. [CrossRef]

69. Daly, K.A.; Liu, S.; Agrawal, V.; Brown, B.N.; Huber, A.; Johnson, S.A.; Reing, J.; Sicari, B.; Wolf, M.; Zhang, X.; et al. The host response to endotoxin-contaminated dermal matrix. Tissue Eng. Part A 2012, 18, 1293-1303. [CrossRef]

70. Lu, X.; Zhang, H.; Huang, Y.; Zhang, Y. A proteomics study to explore the role of adsorbed serum proteins for PC12 cell adhesion and growth on chitosan and collagen/chitosan surfaces. Regen. Biomater. 2018, 5, 261-273. [CrossRef]

(C) 2020 by the authors. Licensee MDPI, Basel, Switzerland. This article is an open access article distributed under the terms and conditions of the Creative Commons Attribution (CC BY) license (http://creativecommons.org/licenses/by/4.0/). 